\title{
РОЛЬ МИКРООКРУЖЕНИЯ В ИНДУЦИРОВАННОЙ in vitro ГЕМОПОЭТИЧЕСКОЙ ДИФФЕРЕНЦИРОВКЕ МЫШИНЫХ ЭМБРИОНАЛЬНЫХ СТВОЛОВЫХ КЛЕТОК
}

\author{
(обзор)
}

\section{И.П. САВЧЕНКОВА}

Моноциты и макрофаги служат мишенями для многих лентивирусов животных, в том числе вируса инфекционной анемии лошадей (И.П. Савченкова с соавт., 2017). Сложность патогенеза и недостаточная изученность ретровирусных инфекций обусловливают необходимость поиска адекватной клеточной модели для их изучения in vitro. В связи с этим получение макрофагов в процессе направленной дифференцировки эмбриональных стволовых клеток (ЭСК), в том числе генетически трансформированных генами лошади, представляет интерес для ветеринарии (И.П. Савченкова с соавт., 2016). Мышиные ЭСК, выделенные из предымплантационных эмбрионов (M.J. Evans с соавт., 1981; G.R. Martin, 1981), имеют уникальные свойства по сравнению с другими типами клеток (Т.С. Doetschman с соавт., 1985; И.П. Савченкова с соавт., 1996; A.M. Wobus c coaвт., 2003), что выражается в их неограниченной способности пролиферировать и формировать при индукции in vitro все типы клеток эмбриона и взрослого организма. Они могут быть ценным источником для получения in vitro всех видов тканей и органов млекопитающих для экспериментального анализа, в том числе для изучения и моделирования раннего гемопоэза в культуре. В обзоре обсуждаются вопросы, связанные с дифференцировкой ЭСК в направлении гемопоэза in vitro (A.L. Olsen с соавт., 2006; I. Orlovskaya с соавт., 2008; J.A. Briggs с соавт., 2017). Для этого используют различные методические подходы, которые имеют свои преимущества и недостатки. Рассматривается влияние цитокинов, факторов роста гемопоэза и фидерных слоев, представленных монослоем стромальных клеток, на дифференцировку ЭСК in vitro. Уделяется внимание непрямому методу дифференцировки посредством создания эмбриональных телец (ЭТ) in vitro и имитации микросреды. Показано влияние микроокружения в процессе цитодифференцировки ЭСК мыши в направлении гемопоэза. Продемонстрировано, что максимальное приближение условий культивирования и дифференцировки in vitro к условиям развития гемопоэза in vivo повышает эффективность гемопоэтической дифференцировки ЭСК. Необходимо продолжать поиск панели факторов, которые избирательно направляют развитие ЭСК в мезодерму и препятствуют их дифференцировке в эктодерму и энтодерму. В настоящее время развиваются методы, позволяющие получать макрофаги в культуре из ЭСК (А. Subramanian с соавт., 2009; L. Zhuang с coaвт., 2012; M. Pittet c соавт., 2014). Приведены данные, в том числе полученные автором настоящего обзора, о роли микроокружения в дифференцировке ЭСК в макрофаги in vitro. Непрямой метод дифференцировки ЭСК посредством создания ЭТ in vitro и имитации микросреды (добавление рекомбинантных цитокинов - интерлейкина 3 и гранулоцитарного макрофагового колониестимулирующего фактора) может рассматриваться как более перспективный подход для получения макрофагов в культуре in vitro. Понимание регуляторных механизмов, управляющих врожденной иммунной системой, сделает изучение лентивирусов, которые обладают тропностью к этим клеткам, более эффективным. Получение из ЭСК в культуре гомогенной клеточной популяции моноцитов и макрофагов открывает новые возможности для изучения зависимости репликации лентивирусов от степени клеточной дифференцировки.

Ключевые слова: мышиные эмбриональные стволовые клетки, эмбриональные тельца, дифференцировка, гемопоэтическая ниша, гемопоэтические стволовые клетки, ростовые факторы, цитокины, мононуклеарная система фагоцитов, лентивирусы, макрофаги, получение, in vitro.

Сложность патогенеза и недостаточная изученность ретровирусных инфекций обусловливают необходимость поиска адекватной клеточной модели для их изучения in vitro. Моноциты и макрофаги служат мишенью для многих лентивирусов животных, в том числе вируса инфекционной анемии лошадей (1). В течение многих лет макрофаги для исследований получали из моноцитов, которые выделяли из периферической крови животных, для чего требовалось ее значительное количество. Использование нескольких доноров приводило к необходимости многократного взятия у них крови,

* Работа выполнялась по теме НИР № 0578-2014-0028 «Изучить стволовые клетки в качестве новой клеточной системы для лентивирусов животных in vitro». 
поскольку диплоидные макрофаги размножаются в культуре ограниченное время. Предпринимались попытки создать иммортализованные (бессмертные) культуры макрофагов собаки (DH82) (2) и лошади (EML-3C, e-Cas) $(3,4)$, чувствительных к инфекционной анемии, которые депонированы в Американскую Коллекцию культур клеток (American Type Culture Collection, ATCC®, https://www.lgcstandards-atcc.org/Products/Cells_and_Microorganisms/Cell_Lines.aspx?geo_country=ru). Однако оказалось, что линия перевиваемых макрофагов лошади е-Cas - это мышиные макрофаги (5). В связи с этим получение макрофагов в процессе направленной дифференцировки мышиных эмбриональных стволовых клеток (ЭСК) in vitro, в том числе генетически-трансформированных генами лошади, представляет интерес для ветеринарии.

ЭСК млекопитающих - перспективный клеточный материал для изучения вопросов, связанных с цитодифференцировкой (6). Мышиные ЭСК, выделенные из предымплантационных эмбрионов в 1981 году $(7,8)$, имеют уникальные свойства (9-11) по сравнению с другими типами клеток. В них выявлена огромная библиотека предсинтезированных мРНК генов раннего эмбриогенеза и органогенеза. Установлена способность отвечать на все сигналы, которые регулируют эмбриогенез, причем временной порядок включения основных генов развития совпадает в постымплантационных зародышах и в культуре эмбриональных телец (ЭТ) (12). Это позволяет создавать модельные системы in vitro, которые повторяют эмбриональные события, с целью выявления генов и молекулярных сигналов, ответственных за судьбу клеточной специализации и пролиферации, что открывает огромные возможности для изучения функциональных программ генома млекопитающих. ЭСК имеют неограниченную способность формировать in vitro все типы клеток эмбриона и взрослого организма, в том числе трофобласт и половые клетки (13). Они могут рассматриваться в качестве ценного источника для получения in vitro всех видов тканей и органов млекопитающих для экспериментального анализа (14-16), в том числе для изучения и моделирования раннего гемопоэза в культуре (17-19).

Первые исследования, в которых пытались добиться развития гемопоэза в мышиных ЭСК, включали получение гемопоэтических стволовых клеток (ГСК) (20) и определение роли отдельных факторов в их формировании (21-23). Используемые экспериментальные подходы носили эмпирический характер, и знания, касающиеся онтогенеза кроветворной системы, не применялись. Оценка дифференцировки ЭСК в ГСК базировалась на морфологических изменениях и изучении экспрессии генов - маркеров гемопоэза $(24,25)$. Создание клонов и их анализ in vitro редко использовались для оценки эффективности получения ГСК и более специализированных клеток крови. Недостаток знаний о клеточной структуре гемопоэтической ниши млекопитающих из-за ее сложности объясняет неспособность восстановить микроокружение в условиях in vitro для поддержания и расширения ГСК и их производных.

Уместным будет напомнить, что концепция гемопоэтической ниши была введена более трех десятилетий назад (26). C тех пор наше понимание биологии ниши значительно расширилось (27-29). В настоящее время принято считать, что строма костного мозга (ее клеточные и внеклеточные компоненты) играет ключевую роль в регуляции самообновления ГСК и их специализации. В связи с этим для индукции дифференцировки ЭСК в гемопоэтическую линию разрабатываются методы, которые включают использование фидерных слоев, представленных монослоем клеток различного происхождения, в том числе продуцирующих факторы для поддер- 
жания гемопоэза, непрямую дифференцировку посредством образования ЭТ в культуре, добавление смеси ростовых факторов, а также различные комбинации этих протоколов (30-32).

Целью настоящего обзора стало обсуждение подходов, основанных на имитации ниши in vitro и используемых для дифференцировки эмбриональных стволовых клеток в гемопоэтическом направлении, а также возможности получения из ЭСК макрофагов.

Дифференцировка мышиных ЭСК с использова н и е м фиде рных слое в. Функция клеток ниши опосредуется молекулами, ассоциированными с клеточной мембраной, растворимыми факторами и молекулами внеклеточного матрикса, которые продуцируют эти же клетки. Попытки восстановить функциональную гемопоэтическую нишу in vitro пока не увенчались успехом, однако привели к созданию поддерживающих кроветворение клеточных линий. Было показано, что в процессе регуляции самообновления ГСК в костном мозге принимают участие остеобласты, эндотелиальные и фибробластоподобные клетки (33-35). Некоторые из этих клеточных линий были успешно применяются в качестве индукторов дифференцировки ЭСК мыши в гемопоэтическом направлении $(36,37)$. Использование поддерживающих монослоев клеток (фидеров) поможет выявить молекулы, которые важны для дифференцировки ЭСК. В настоящее время в качестве фидерных слоев используют различные стромальные клетки, выделенные из эмбриональной печени, костного мозга и стромально-васкулярной фракции подкожно-жировой ткани. Показано, что такое культивирование в одиночку или в сочетании с факторами роста служит успешным методическим подходом для индукции гемопоэтической дифференцировки ЭСК in vitro.

Одна из первых клеточных линий, которая была использована для индукции дифференцировки мышиных ЭСК в гемопоэтические клетки, линия стромальных клеток ОР9, полученная из костного мозга мутантных мышей (23). Из-за мутации в гене $M$ - CSF клетки не продуцируют функциональный макрофаговый колониестимулирующий фактор (M-CSF). M-CSF - цитокин, который участвует в пролиферации, дифференцировке и поддержании моноцитов и макрофагов. Клетки с дефектным геном $M$ - CSF его не секретируют, поэтому их использование в качестве фидерного слоя могло препятствовать дифференцировке ЭСК в макрофаги. Позднее было продемонстрировано, что M-CSF не влияет на способность фидерных клеток поддерживать гемопоэтическую дифференцировку ЭСК (24). Культивирование ЭСК на фидерных слоях, представленных клетками ОР9, приводило к образованию ГСК в культуре, из которых потом получали эритроциты, миелоидные и лимфоидные клетки (38). Дифференцировка ЭСК в гемопоэтическом направлении с использованием ОР9 была более эффективной при добавлении в питательную среду ростовых факторов, которые поддерживают гемопоэз. Так, культивирование ЭСК на монослое клеток OP9 в сочетании с тромбопоэтином и интерлейкинами 6 и 11 (IL6 и IL-11), которые поддерживают линию мегакариоцитов в костном мозге, привело к формированию мегакариоцитов in vitro, продуцирующих тромбоциты (39).

Имеются сообщение об успешном использовании стромальных клеток костного мозга линии MS-5 в качестве фидерного слоя для индукции дифференцировки ЭСК в мегакариоциты. В среду дополнительно вносили тромбопоэтин (Тро), фактор роста фибробластов 2 (FGF-2), эритропоэтин (Еро), фактор роста гепатоцитов (HGF), фактор роста стволовых клеток (SCF), смесь интерлейкинов 3, 6, 11 (IL-3, IL-6, IL-11) и гранулоцитарный 
колониестимулирующий фактор роста (G-CSF) (40-42).

Ранее сообщалось о применении стромальной линии клеток ST2, выделенной из костного мозга мышей, для индукции дифференцировки ЭСК (43). На первом этапе ЭСК культивировали в полужидкой метилцеллюлозной среде (МТ), затем клетки отмывали и культивировали на монослое клеток ST2 в присутствии интерлейкина 7 (IL-7) - фактора, который, как известно, направляет развитие взрослых ГСК в лимфоидную линию. Авторы показали, что в этой системе совместного культивирования ЭСК способны образовывать незрелые предшественники лимфоцитов, которые могут специализироваться далее в зрелые В- и Т-лимфоциты in vitro.

В качестве фидерного слоя успешно использовали клетки, выделенные из стромально-васкулярной фракции подкожного жира РА6 $(44,45)$. Представляют интерес данные по изучению мультипотентных мезенхимных стволовых клеток в качестве фидерных слоев для индукции дифференцировки ЭСК в гемопоэтическом направлении (46-48).

Дифференцировка ЭСК посредством создания эмбриональных телец с последующей имитацией микроо к р у же н и я. Процесс дифференцировки ЭСК зависит не только от определенных молекулярных стимулов, которые могут создавать фидерные слои и смеси цитокинов, но и от конкретных физических условий, в которых культивируются клетки. Описано, в том числе нами (49), что ЭСК в культуре стремятся создать трехмерные структуры, которые напоминают раннее развитие эмбрионов. В этих структурах, названных эмбриональные тельца (ЭТ), развиваются различные типы клеток, включая гемангиобласт - стволовые клетки, предшественники ГСК (гемоцитобласт) и стволовой клетки эндотелия кровеносного сосуда (ангиобласт). Основная особенность дифференцировки мышиных ЭСК in vitro - этапность. Вся дифференцировка ЭСК происходит через формирование вначале простых, затем сложных цистических ЭТ $(9,10)$. В отличие от мышиных ЭСК, у большинства линий ЭСК человека отсутствует стадия формирования простых ЭТ in vitro вследствие гетерогенности колоний (50).

Для получения ЭТ используются различные методы: обеднение условий культивирования, создание высокой плотности посева клеток, блокирование клеточной адгезии посредством культивирования их в чашках Петри с ультранизким прикреплением $(51,52)$; создание подвесных капельных культур (53-55); использование для культивирования метилцеллюлозы (MT) или других полужидких сред или культивирование в пористых губках $(56,57)$. На первом этапе во всех перечисленных методах ЭСК индуцируют К дифференцировке посредством изменения условий культивирования: удаления фидерного слоя и факторов, препятствующих дифференцировке, например LIF (фактор, подавляющий лейкемию). Применяется также изменение концентрации клеток для посева или плотности фидерного слоя, необычные методы снятия ЭСК с подложки, создание условий для суспензионного культивирования. Все перечисленные манипуляции ведут к образованию на 4-е сут культивирования простых ЭТ - трехмерных сферических структур, состоящих из клеток на начальных стадиях дифференцировки. Наружный слой таких телец представлен энтодермальными клетками. Они образуют базальную мембрану, напоминающую мембрану Рейхарта, компоненты которой синтезируется в нормальном эмбриогенезе клетками париетальной энтодермы. В центре простых ЭТ остается популяция недифференцированных ЭСК, которые продолжают делиться. Если культивирование в суспензии происходит более 4 сут, то из простых ЭТ формируют цистические ЭТ. Для них характерно наличие внутри полости, 
которая наполнена жидкостью, а внутренняя поверхность ЭТ выстлана эктодермальными цилиндрическими клетками. Если такие агрегаты перенести на поверхность, способствующую адгезии, например покрытую желатином, то цистические ЭТ прикрепляются к субстрату, и начинается процесс миграции клеток. В течение 9 сут или более образуется много типов клеток, детерминированных к дифференцировке. Процесс дифференцировки в таком случае имеет хаотичный характер (58). Недостаток подобной дифференцировки в том, что в ЭТ присутствуют разные типы клеток и получить много клеток одного специализированного вида сложно. Клетки в момент миграции из ЭТ, когда происходит «распластывание» последних на желатинизированной поверхности, становятся чувствительны к воздействию различных индукторов цитодифференцировки. Поэтому на указанном этапе проводится обработка индукторами направленной дифференцировки (14). На сегодняшний день существуют протоколы получения ЭТ из ЭСК с высокой эффективностью (59-61). Гемопоэтическая дифференцировка ЭСК посредством создания культуры ЭТ считается непрямым методом дифференцировки (62) и имеет преимущество перед другими методами (63-65). Интересно, что частота формирования гемопоэтических предшественников при использовании различных методов формирования ЭТ схожа (63). Исследования показали, что культивирование клеток на микроносителях, представленных полимерами, обеспечивает значительное повышение эффективности дифференцировки ЭСК $(66,67)$.

ЭСК можно культивировать как отдельные клетки, кластеры (20 клеток) и колонии (более 200 клеток). Количество ЭСК можно контролировать и обеспечить формирование ЭТ желаемого размера $(68,69)$. ЭТ культивируются в средах с добавлением индукторов дифференцировки ЭСК или без них с целью оценки спонтанной дифференцировки ЭСК. Получение ГСК из мышиных ЭТ было более эффективным при добавлении в индукционную среду IL-6 или в комбинации с IL-3 и SCF (70). Добавление Еро при культивировании ЭТ в полужидкой среде, представленной МТ, значительно активировало дифференцировку ЭСК в эритроциты по сравнению с дифференцировкой, индуцированной в среде без него. Формирование миелоидной линии из ЭТ усиливалось посредством добавления IL-3 (71) и в сочетании с IL-1 и M-CSF или GM-CSF (гранулоцитарный макрофаговый колониестимулирующим фактор) (72).

Следовательно, знание факторов, которые участвуют в регуляции этапов развития кроветворной системы в онтогенезе, включая факторы, регулирующие индукцию мезодермы и последующее образование гемангиобласта и ГСК, играет ключевую роль в индукции ЭСК в направлении гемопоэза. Получение новых данных позволит улучшить существующие и разработать новые методы для создания специализированных гомогенных популяций клеток крови и иммунной системы in vitro, в том числе с заданными свойствами. Из ЭСК были созданы все типы клеток крови и иммунной системы: эритроциты, мегакариоциты, гранулоциты, тучные клетки, эозинофиллы, Т- и В-лимфоциты, дендритные клетки и макрофаги (73-75), в том числе человека (76).

К вопросу о получении макрофагов из ЭСК in vitro. В последнее время основные представления о мононуклеарной системе фагоцитов (МСФ) оспариваются в связи с накоплением новых экспериментальных данных $(77,78)$, к которым относятся существование отдельной линии эмбриональных фагоцитов, способность к трансдифференцировке (процессу прямого преобразования) и слиянию клеток МСФ с другими типами клеток, доказательство локального обновления популяций тканевых 
макрофагов в отличие от моноцитов, а также открытие дендритных клеток как отдельной линии мононуклеарных фагоцитов, специализирующихся на презентации антигена Т-клеткам и инициации и контроле иммунитета. Ранее система МСФ была определена как линия гемопоэтических клеток, происходящая из клеток-предшественников в костном мозге. Концепция клеточной системы, основанная на едином клеточном происхождении, была привлекательной в связи с тем, что объединила многие аспекты изучения врожденного иммунитета. В настояшее время существует две гипотезы, одна из которых предполагает фрагментацию МСФ на подмножества с различными специализациями и состояниями активности, а другая постулирует, что границы между мононуклеарными фагоцитами и другими миелоидными клетками, даже другими типами мезодермальных клеток, размыты. Тем не менее считается, что МСФ включает популяции моноцитов, макрофагов и дендритных клеток на разных стадиях дифференцировки и активации $(79,80)$. Тканевые макрофаги - высокоспециализированные клетки, которые широко распространены во всех тканях и служат ключевым компонентом иммунной системы. Они принимают активное участие в восстановлении тканей при ишемическом повреждении органов, травме сосудов и презентации антигенов и в разных тканях могут проявлять значительную гетерогенность в отношении фенотипа, гомеостатического обмена и функции. Вопросы о происхождении и обновлении подмножеств макрофагов ткани остаются противоречивыми (79).

Понимание регуляторных механизмов, управляющих врожденной иммунной системой, может сделать изучение лентивирусов, обладающих тропностью к макрофагам, более эффективным. Получение из ЭСК в культуре гомогенной клеточной популяции, представленной моноцитами или макрофагами, открывает новые возможности для изучения зависимости репликации лентивирусов от степени цитодифференцировки. Анализ данных литературы показал, что исследования в этом направлении ведутся (81). Был описан метод получения функциональных моноцитов и макрофагов из ЭСК, который включает спонтанную дифференцировку ЭСК в ЭТ с последующей направленной дифференцировкой по миелоидной линии (82). В среду добавляли рекомбинантные цитокины IL-3 и M-CSF для получения гомогенной популяции моноцитов, из которых далее образовывались макрофаги. По своим свойствам (фенотип и функциональные способности) они были схожи с макрофагами, полученными из моноцитов крови. Используя этот метод, в течение 1-3 нед можно получить более $1 \times 10^{7}$ моноцитов из 6-луночного планшета, однако затем эффективность резко снижается. Кроме того, была выявлена зависимость числа моноцитов от используемой для этих целей линии ЭСК.

На сегодняшний день разработаны методы получения макрофагов в культуре как из ЭСК мыши $(81,83,84)$, так и человека (85). Они включают культивирование ЭСК на стромальных клетках мыши (например, OP9) и/или очистку клеток-предшественников от частично дифференцированных культур на стадии дифференцировки в моноциты. Однако ни один из этих протоколов не поддается масштабированию в связи с тем, что условия получения в культуре макрофагов определены не полностью.

На сайте http://www.abcam.com компании «Abcam Inc.» (Великобритания) опубликован пошаговый протокол получения макрофагов из мышиных ЭСК линии Е14, взятый из работы L. Zhuang с соавт. (84). Этот метод предлагает использовать 15 \% кондиционную среду (КС), собранную из-под клеток мышиной фибросаркомы L929, которая содержит колониестимулирующий фактор 1 (CGF-1), он же M-CSF. Непонятна про- 
пись приготовления среды для дифференцировки ЭСК в макрофаги, а именно добавление в среду LIF, который позволяет культивировать ЭСК, сохраняя их эмбриональный фенотип без признаков дифференцировки. Сама идея многократного сбора среды при культивировании ЭТ, содержащей в суспензии клетки с фенотипом макрофагов, оригинальна. Метод позволяет получить с одной чашки Петри $12 \times 10^{6}-24 \times 10^{6}$ макрофагов в течение 10-20 сут посредством многократного накопления.

Мы также проводили исследования по получению макрофагов из мышиных ЭСК посредством дифференцировки $(86,87)$. В качестве объекта использовали линию Д3. Дифференцировку выполняли через образование ЭТ в культуре. Обеднение условий культивирования ЭСК с последующим переводом их в суспензионное состояние приводило к образованию на 2-е сут ЭТ с высокой эффективностью $(99 \pm 0,02 \%)$. Культивирование ЭТ в течение 12 сут в суспензии в среде, которая содержала $25 \%$ КС из мышиных клеток, выделенных из стромы костного мозга, способствовало их дифференцировке в гемопоэтическом направлении. На 12-е сут культивирования ЭТ собирали и обрабатывали ферментами для получения отдельных клеток. Доля клеток, положительно окрашенных с антителами (АТ) против антигенов, экспрессия которых специфична для гемопоэтических клеток CD34 (сиаломуцин) и CD45 (общий лейкоцитарный антиген), составила соответственно 37 и 5 \%. Для подтверждения дифференцировки использовали полужидкую МТ среду, в которую дополнительно вносили $25 \%$ КС. Анализ полученных результатов продемонстрировал формирование клонов с различной морфологией на 14-е сут с эффективностью 0,11\%

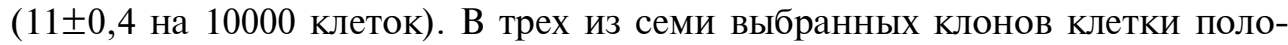
жительно окрашивались с АТ против F4/80 (экспрессия этого антигена специфична для макрофагов). Когда вместо КС в среду вносили рекомбинантные IL 3 и GM-CSF, доля клеток, положительно окрашенных AT против антигенов CD34 и CD45, составляла соответственно 43 и $25 \%$. Эффективность колоний с морфологией подобной макрофагам в МТ среде с цитокинами увеличивалась в 3 раза. Наши результаты свидетельствуют о возможности получения клеток с фенотипом, подобным макрофагам, из ЭСК посредством непрямой дифференцировки популяций.

Таким образом, мышиные эмбриональные стволовые клетки, выделенные из предымплантационных эмбрионов, имеют уникальные свойства и могут рассматриваться в качестве ценного материала для изучения и моделирования раннего гемопоэза в культуре. Для этого используются различные методические подходы, которые имеют свои преимущества и недостатки. Ключевую роль в индукции дифференцировки ЭСК мыши в гемопоэтическом направлении играют цитокины, факторы роста гемопоэза и фидерные слои, представленные монослоем стромальных клеток. Непрямой метод дифференцировки ЭСК посредством создания эмбриональных телец in vitro и имитации микросреды (добавление рекомбинантных цитокинов) может рассматриваться как более перспективный метод получения в культуре макрофагов. Можно сделать вывод, что максимальное приближение условий культивирования и дифференцировки in vitro к условиям развития гемопоэза in vivo повышает эффективность гемопоэтической дифференцировки ЭСК. Несмотря на огромный интерес к рассмотренным вопросам и на увеличивающееся число методов, проблема низкой эффективности дифференцировки ЭСК в кроветворные линии, в том числе в макрофаги, остается не решенной. Необходимо продолжать поиск панели факторов, которые избирательно направляют развитие ЭСК в мезодерму и препятствуют формированию из них эктодермы и энтодермы. Следует научиться 
управлять этим процессом, чтобы стимулировать избирательно дифференцировку мезодермы в гемангиобласт и далее в гемопоэтические стволовые клетки, возможно, посредством подбора соответствующей микросреды, которая будет регулировать экспрессию желаемых генов, контролирующих кроветворение.

\author{
ФГБНУ ФНЦ Всероссийский НИИ экспериментальной \\ ветеринарии им. К.И. Скрябина и Я.Р. Коваленко РАН, \\ 109428 Россия, г. Москва, Рязанский пр., 24, корп. 1, \\ e-mail: s-ip@mail.ru $\square$
}

Поступила в редакцию 15 мая 2020 года

\title{
THE ROLE OF MICROENVIRONMENT IN THE in vitro DIRECTED HEMATOPOIETIC PATHWAY OF MURINE EMBRYONIC STEM CELL DIFFERENTIATION (review)
}

\section{I.P. Savchenkova}

Federal Science Center Skryabin and Kovalenko All-Russian Research Institute of Experimental Veterinary RAS, 24/1, Ryazanskii pr., Moscow, 109428 Russia, e-mail s-ip@mail.ru ( $₫$ corresponding author) ORCID:

Savchenkova I.P. orcid.org/0000-0003-3560-5045

The authors declare no conflict of interests

Acknowledgements:

The work was carried out for the topic of research studies No. 0578-2014-0028 "To study stem cells as a new cellular system for animal lentiviruses in vitro"

Received May 15, 2020

doi: 10.15389/agrobiology.2020.4.659eng

\section{Abstract}

Monocytes and macrophages are the targets for many animal lentiviruses, including the equine infectious anemia virus (I.P. Savchenkova et al., 2017). The complexity of the pathogenesis and insufficient knowledge of retroviral infections necessitate the search for an adequate cell model for their in vitro study. In this regard, obtaining macrophages via directed differentiation of embryonic stem cells (ESCs) in vitro, including those genetically transformed with equine gene, is of interest for veterinary medicine (I.P. Savchenkova et al., 2016). Mouse ESCs isolated from preimplantation embryos (M.J. Evans et al., 1981; G.R. Martin, 1981) have unique properties compared to other cell types (T.C. Doetschman et al., 1985; I.P. Savchenkova et al., 1996; A.M. Wobus et al., 2003), namely an unlimited capacity to proliferate and form all types of cells of the embryo and adult organism in vitro. They can be a valuable source for in vitro production of all types of mammalian tissues and organs for experimental research, including for the study and modeling of early hematopoiesis in in vitro culture. The review discusses issues related to the in vitro hematopoietic differentiation of ESCs (A.L. Olsen et al., 2006; I. Orlovskaya et al., 2008; J.A. Briggs et al., 2017). For this, various methodological approaches are used, which have advantages and disadvantages. Effects of cytokines, hematopoietic growth factors, and feeder layers, e.g. a monolayer of stromal cells, on differentiation in vitro of ESCs are under consideration. The attention extremely focuses on indirect method of differentiation by creating embryonic bodies (EBs) in vitro and simulating a microenvironment for differentiation. The microenvironment is shown to activate the hematopoietic cytodifferentiation pathways in mouse ESCs. It has been demonstrated that the conditions of culture and differentiation in vitro closest to those enabling hematopoiesis development in vivo, increases the efficiency of hematopoietic differentiation of ESCs. It is necessary to continue the search for a panel of factors that selectively direct the development of ESCs in the mesoderm and prevent their differentiation into ectoderm and endoderm. Obtaining new data will improve existing and develop new methods for creating specialized homogeneous populations of blood cells and the immune system in vitro with desired properties. Methods are currently being developed that make it possible to obtain macrophages in culture from ESCs (A. Subramanian et al., 2009; L. Zhuang et al., 2012; M. Pittet et al., 2014). Data are presented, including the author's own findings, on the role of the microenvironment in the differentiation of ESCs in macrophages in vitro. An indirect method of ESC differentiation through the creation of ETs in vitro and imitation of the microenvironment (addition of recombinant cytokines, the interleukin 3 and granulocyte macrophage colony-stimulating factor) can be considered as a more promising way to obtain macrophages in in vitro culture. An understanding of the regulatory mechanisms that drive the innate immune system may contribute to more effective research on lentiviruses with tropism for these cells. Production of monocytes and macrophages from ESCs in a culture of homogeneous cell 
population opens up new opportunities for studying the dependence of replication lentiviruses on the degree of cell differentiation.

Keywords: mouse, embryonic stem cells, embryonic bodies, differentiation, hematopoietic niche, hematopoietic stem cells, growth factors, cytokines, mononuclear phagocyte system, lentiviruses, macrophages, production, in vitro culture.

\section{REFERENCES}

1. Savchenkova I.P., Yurov K.P. Veterinariya i kormlenie, 2017, 6: 6-10 (in Russ.).

2. Hines R., Maury W. DH82 cells: a macrophage cell line for the replication and study of equine infectious anemia virus. Journal of Virological Methods, 2001, 95(1-2): 47-56 (doi: 10.1016/s01660934(01)00288-9).

3. Fidalgo-Carvalho I., Craigo J.K., Barnes S., Costa-Ramos C., Montelaro R.C. Characterization of an equine macrophage cell line: application to studies of EIAV infection. Veterinary Microbiology, 2009, 136(1-2): 8-19 (doi: 10.1016/j.vetmic.2008.10.010).

4. Werners A.H., Bull S., Fink-Gremmels J., Bryant C.E. Generation and characterisation of an equine macrophage cell line (e-CAS cells) derived from equine bone marrow cells. Veterinary Immunology and Immunopathology, 2004, 97(1-2): 65-76 (doi: 10.1016/j.vetimm.2003.08.012).

5. Evans E., Paillot R., López-Álvarez M.R. A comprehensive analysis of e-CAS cell line reveals they are mouse macrophages. Sci. Rep., 2018, 8(1): 8237 (doi: 10.1038/s41598-018-26512-3).

6. Savchenkova I.P., Alekseenkova S.V., Yurov K.P. Voprosy virusologii, 2016, 61(3): 107-111 (doi: 10.18821/0507-4088-2016-61-3-107-111) (in Russ.).

7. Evans M.J., Kaufman M.H. Establishment in culture of pluripotential cells from mouse embryos. Nature, 1981, 292: 154-156 (doi: 10.1038/292154a0).

8. Martin G.R. Isolation of a pluripotent cell line from early mouse embryos cultured in medium conditioned by teratocarcinoma stem cells. Proceedings of the National Academy of Sciences, 1981, 78(12): 7634-7638 (doi: 10.1073/pnas.78.12.7634).

9. Bradley A., Evans M., Kaufman M.H., Robertson E. Formation of germ-line chimaeras from embryo-derived teratocarcinoma cell lines. Nature, 1984, 309: 255-256 (doi: 10.1038/309255a0).

10. Doetschman T.C., Eistetter H., Katz M., Schmidt W., Kemler R. The in vitro development of blastocyst-derived embryonic stem cell lines: formation of visceral yolk sac, blood islands and myocardium. J. Embryol. Exp. Morphol., 1985, 87: 27-45.

11. Savchenkova I.P., Zinov'eva N.A., Bulla I., Brem G. Uspekhi sovremennoi biologii, 1996, 116(1): 78-91 (in Russ.).

12. Savchenkova I.P. Embrional'nye stvolovye kletki v biologii: nastoyashchee i budushchee [Embryonic stem cells in biology: the current state of the art and future challenges]. Dubrovitsy, 1999 (in Russ.).

13. Savchenkova I.P. Problemy reproduktsii, 2009, 15(3): 54-59 (in Russ.).

14. Wobus A.M., Boheler K.R. Embryonic stem cells: prospects for developmental biology and cell therapy. Physiological Reviews, 2005, 85(2): 635-678 (doi: 10.1152/physrev.00054.2003).

15. Nakano T. Hematopoietic stem cells: generation and manipulation. Trends Immunol., 2003, 24(11): 589-594 (doi: 10.1016/j.it.2003.09.003).

16. Kennedy M., Keller G.M. Hematopoietic commitment of ES cells in culture. Methods in Enzymology, 2003, 365: 39-59 (doi: 10.1016/s0076-6879(03)65003-2).

17. Olsen A.L., Stachura D.L., Weiss M.J. Designer blood: creating hematopoietic lineages from embryonic stem cells. Blood, 2006, 107(4): 1265-1275 (doi: 10.1182/blood-2005-09-3621).

18. McKinney-Freeman S.L., Daley G.Q. Towards hematopoietic reconstitution from embryonic stem cells: a sanguine future. Current Opinion in Hematology, 2007, 14(4): 343-347 (doi: 10.1097/MOH.0b013e3281900edd).

19. Tian X., Kaufman D.S. Differentiation of embryonic stem cells towards hematopoietic cells: progress and pitfalls. Current Opinion in Hematology, 2008, 15(4): 312-318 (doi: 10.1097/MOH.0b013e328302f429).

20. Wiles M.V., Keller G. Multiple hematopoietic lineages develop from embryonic stem (ES) cells in culture. Development, 1991, 111(2): 259-267.

21. Burkert U., von Rüden R.T., Wagner E.F. Early fetal hematopoietic development from in vitro differentiated embryonic stem cells. The New Biologist, 1991, 3: 698-708.

22. Schmitt R.M., Bruyns E., Snodgrass H.R. Hematopoietic development of embryonic stem cells in vitro: cytokine and receptor gene expression. Genes \& Dev., 1991, 5: 728-740 (doi: 10.1101/gad.5.5.728).

23. Nakano T., Kodama H., Honjo T. Generation of lymphohematopoietic cells from embryonic stem cells in culture. Science, 1994, 265(5175): 1098-1101 (doi: 10.1126/science.8066449).

24. Nakano T. In vitro development of hematopoietic system from mouse embryonic stem cells: a new approach for embryonic hematopoiesis. Int. J. Hematol., 1996, 65(1): 1-8 (doi: 10.1016/s0925-5710(96)00531-2). 
25. Ling V., Neben S. In vitro differentiation of embryonic stem cells: immunophenotypic analysis of cultured embryoid bodies. J. Cell Physiol., 1997, 171(1): 104-115 (doi: 10.1002/(SICI)10974652(199704) 171:1<104::AID-JCP12>3.0.CO;2-G).

26. Schofield R. The stem cell system. Biomedicine \& Pharmacotherapy, 1983, 37(8): 375-380.

27. Spangrude G.J. Future challenges for hematopoietic stem cell research. Biotechniques, 2003, 35(6): 1273-1279 (doi: 10.2144/03356ss07).

28. Beerman I., Luis T.C., Singbrant S., Lo Celso C., Méndez-Ferrer S. The evolving view of the hematopoietic stem cell niche. Exp. Hematol., 2017, 50: 22-26 (doi: 10.1016/j.exphem.2017.01.008).

29. Szade K., Gulati G.S., Chan C.K.F., Kao K.S., Miyanishi M., Marjon K.D., Sinha R., George B.M., Chen J.Y., Weissman I.L. Where hematopoietic stem cells live: the bone marrow niche. Antioxidants \& Redox Signaling, 2018, 29(2): 191-204 (doi: 10.1089/ars.2017.7419).

30. Kearney J.B., Bautch V.L. In vitro differentiation of mouse ES cells: hematopoietic and vascular development. Methods in Enzymology, 2003, 365: 83-98 (doi: 10.1016/s0076-6879(03)65006-8).

31. Fraser S.T., Yamashita J., Jakt L.M., Okada M., Ogawa M., Nishikawa S., Nishikawa S.-I. In vitro differentiation of mouse embryonic stem cells: hematopoietic and vascular cell types. Methods in Enzymology, 2003, 365: 59-72 (doi: 10.1016/s0076-6879(03)65004-4).

32. Orlovskaya I., Schraufstatter I., Loring J., Khaldoyanidi S. Hematopoietic differentiation of embryonic stem cells. Methods, 2008, 45(2): 159-167 (doi: 10.1016/j.ymeth.2008.03.002).

33. Weisel K.C., Gao Y., Shieh J.H., Moore M.A. Stromal cell lines from the aorta-gonado-mesonephros region are potent supporters of murine and human hematopoiesis. Exp. Hematol., 2006, 34(11): 1505-1516 (doi: 10.1016/j.exphem.2006.06.013).

34. Calvi L.M., Adams G.B., Weibrecht K.W., Weber J.M., Olson D.P., Knight M.C., Martin R.P., Schipani E., Divieti P., Bringhurst F.R., Milner L.A., Kronenberg H.M., Scadden D.T. Osteoblastic cells regulate the haematopoietic stem cell niche. Nature, 2003, 425(6960): 841-846 (doi: 10.1038 /nature02040).

35. Kiel M.J., Yilmaz O.H., Iwashita T., Yilmaz O.H., Terhorst C., Morrison S.J. SLAM family receptors distinguish hematopoietic stem and progenitor cells and reveal endothelial niches for stem cells. Cell, 2005, 121(7): 1109-1121 (doi: 10.1016/j.cell.2005.05.026).

36. Taichman R.S., Reilly M.J., Emerson S.G. The hematopoietic microenvironment: osteoblasts and the hematopoietic microenvironment. Hematology, 2000, 4(5): 421-426.

37. Filippi M.D., Porteu F., Le Pesteur F., Rameau P., Nogueira M.M., Debili N., Vainchenker W., de Sauvage F.J., Kupperschmitt A.D., Sainteny F. Embryonic stem cell differentiation to hematopoietic cells: a model to study the function of various regions of the intracytoplasmic domain of cytokine receptors in vitro. Exp. Hematol., 2000, 28(12): 1363-1372 (doi: 10.1016/s0301472x(00)00549-x).

38. Nakano T., Era T., Takahashi T., Kodama H., Honjo T. Development of erythroid cells from mouse embryonic stem cells in culture: potential use for erythroid transcription factor study. Leukemia, 1997, 11(Suppl. 3): 496-500.

39. Kitajima K., Tanaka M., Zheng J., Sakai-Ogawa E., Nakano T. In vitro differentiation of mouse embryonic stem cells to hematopoietic cells on an OP9 stromal cell monolayer. Methods Enzymol., 2003, 365: 72-83 (doi: 10.1016/s0076-6879(03)65005-6).

40. Uzan G., Prandini M.H., Rosa J.P., Berthier R. Hematopoietic differentiation of embryonic stem cells: an in vitro model to study gene regulation during megakaryocytopoiesis. Stem Cells, 1996, 14(Suppl. 1): 194-199 (doi: 10.1002/stem.5530140725).

41. Berthier R., Prandini M.H., Schweitzer A., Thevenon D., Martin-Sisteron H., Uzan G. The MS5 murine stromal cell line and hematopoietic growth factors synergize to support the megakaryocytic differentiation of embryonic stem cells. Exp. Hematol., 1997, 25(6): 481-49.

42. Eto K., Murphy R., Kerrigan S.W., Bertoni A., Stuhlmann H., Nakano T., Leavitt A.D., Shattil S.J. Megakaryocytes derived from embryonic stem cells implicate CalDAG-GEFI in integrin signaling. Proceedings of the National Academy of Sciences, 2002, 99(20): 12819-12824 (doi: 10.1073/pnas.202380099).

43. Nisitani S., Tsubata T., Honjo T. Lineage marker-negative lymphocyte precursors derived from embryonic stem cells in vitro differentiate into mature lymphocytes in vivo. International Immunology, 1994, 6(6): 909-916 (doi: 10.1093/intimm/6.6.909).

44. Shimizu N., Noda S., Katayama K., Ichikawa H., Kodama H., Miyoshi H. Identification of genes potentially involved in supporting hematopoietic stem cell activity of stromal cell line MC3T3-G2/PA6. Int. J. Hematol., 2008, 87(3): 239-245 (doi: 10.1007/s12185-008-0048-9).

45. Zhang W.J., Park C., Arentson E., Choi K. Modulation of hematopoietic and endothelial cell differentiation from mouse embryonic stem cells by different culture conditions. Blood, 2005, 105: 111-114 (doi: 10.1182/blood-2004-04-1306).

46. Lengerke C., Daley G.Q. Patterning definitive hematopoietic stem cells from embryonic stem cells. Experimental Hematology, 2005, 33(9): $971-979$ (doi: 10.1016/j.exphem.2005.06.004).

47. Gordon-Keylock S.A., Jackson M., Huang C., Samuel K., Axton R.A., Oostendorp R.A., Taylor H., Wilson J., Forrester L.M. Induction of hematopoietic differentiation of mouse embryonic 
stem cells by an AGM-derived stromal cell line is not further enhanced by overexpression of HOXB4. Stem Cells and Development, 2010, 19(11): 1687-1698 (doi: 10.1089/scd.2009.0467).

48. Chen D., Lewis R.L., Kaufman D.S. Mouse and human embryonic stem cell models of hematopoiesis: past, present, and future. Biotechniques, 2003, 35(6): 1253-1261 (doi: 10.2144/03356ss05).

49. Savchenkova I.P., Flyaishmann M., Bulla I., Brem G. Tsitologiya, 1996, 38(10): 1118-1123 (in Russ.).

50. Savchenkova I.P. V knige: Zhivotnaya kletka $v$ kul'ture (metody i primenenie $v$ biotekhnologii) (2-e $i z d$., dopolnennoe). Pod redaktsiei L.P. D'yakonova [Animal cell culture (methods and applications in biotechnology) (2nd ed., revised). L.P. D’yakonov (ed.)]. Moscow, 2009: 347-379 (in Russ.).

51. Konno T., Akita K., Kurita K., Ito Y. Formation of embryoid bodies by mouse embryonic stem cells on plastic surfaces. Journal of Bioscience and Bioengineering, 2005, 100(1): 88-93 (doi: 10.1263/jbb.100.88).

52. Kurosawa H. Methods for inducing embryoid body formation: in vitro differentiation system of embryonic stem cells. Journal of Bioscience and Bioengineering, 2007, 103(5): 389-398 (doi: 10.1263/jbb.103.389).

53. Behringer R., Gertsenstein M., Nagy K.V., Nagy A. Differentiating mouse embryonic stem cells into embryoid bodies by hanging-drop cultures. Cold Spring Harb. Protoc., 2016, 1(12) (doi: 10.1101/pdb.prot092429).

54. Wang X., Yang P. In vitro differentiation of mouse embryonic stem (mES) cells using the hanging drop method. J. Vis. Exp., 2008, 23(17): e825 (doi: 10.3791/825).

55. Carpenedo R.L., Sargent C.Y., McDevitt T.C. Rotary suspension culture enhances the efficiency, yield, and homogeneity of embryoid body differentiation. Stem Cells, 2007, 25(9): 2224-2234 (doi: 10.1634/stemcells.2006-0523).

56. Wu H.-W., Hsiao Y.-H., Chen C.-C., Yet S.-F., Hsu C.-H. A PDMS-based microfluidic hanging drop chip for embryoid body formation. Molecules, 2016, 21(7): 882 (doi: 10.3390/molecules21070882).

57. Liu J.F, Chen Y.M., Yang J.J., Kurokawa T., Kakugo A., Yamamoto K., Gong J.P. Dynamic behavior and spontaneous differentiation of mouse embryoid bodies on hydrogel substrates of different surface charge and chemical structures. Tissue Engineering Part A, 2011, 17(17-18): 23432357 (doi: 10.1089/ten.TEA.2011.0034).

58. Savchenkova I.P. V knige: Zhivotnaya kletka $v$ kul'ture (metody i primenenie v biotekhnologii) /Pod redaktsiei L.P. D'yakonova, V.I. Sit'kova [In: Animal cell culture (methods and applications in biotechnology). L.P. D’yakonov, V.I. Sit'kov (eds.)]. Moscow, 2000: 244-273 (in Russ.).

59. Koike M., Sakaki S., Amano Y., Kurosawa H. Characterization of embryoid bodies of mouse embryonic stem cells formed under various culture conditions and estimation of differentiation status of such bodies. Journal of Bioscience and Bioengineering, 2007, 104(4): 294-299 (doi: 10.1263/jbb.104.294).

60. Brickman J.M., Serup P. Properties of embryoid bodies. WIREs Dev. Biol., 2017, 6(2): e259 (doi: 10.1002/wdev.259).

61. Briggs J.A., Li V.C., Lee S., Woolf C.J., Klein A., Kirschner M.W. Mouse embryonic stem cells can differentiate via multiple paths to the same state. eLife, 2017, 6: e26945 (doi: 10.7554/eLife.26945).

62. Park C., Lugus J.J., Choi K. Stepwise commitment from embryonic stem to hematopoietic and endothelial cells. Current Topics in Developmental Biology, 2005, 66: 1-36 (doi: 10.1016/S00702153(05)66001-2).

63. Dang S.M., Kyba M., Perlingeiro R., Daley G.Q., Zandstra P.W. Efficiency of embryoid body formation and hematopoietic development from embryonic stem cells in different culture systems. Biotechnol Bioeng., 2002, 78(4): 442-53 (doi: 10.1002/bit.10220).

64. Choi K., Chung Y.S., Zhang W.J. Hematopoietic and endothelial development of mouse embryonic stem cells in culture. In: Developmental hematopoiesis. Methods in molecular medicine, vol. 105. M.H. Baron (ed.). Humana Press, Totowa, NJ, 2005: 359-368 (doi: 10.1385/1-59259-8269:359).

65. Shen J., Qu C.K. In vitro hematopoietic differentiation of murine embryonic stem cells. In: Hematopoietic stem cell protocols. Methods in molecular biology ${ }^{\mathrm{TM}}$, vol. 430. K.D. Bunting (ed.). Humana Press, 2008: 103-118 (doi: 10.1007/978-1-59745-182-6_7).

66. Liu H., Roy K. Biomimetic three-dimensional cultures significantly increase hematopoietic differentiation efficacy of embryonic stem cells. Tissue Engineering, 2005, 11(1-2): 319-330 (doi: 10.1089/ten.2005.11.319).

67. Taqvi S., Roy K. Influence of scaffold physical properties and stromal cell coculture on hematopoietic differentiation of mouse embryonic stem cells. Biomaterials, 2006, 27(36): 6024-6031 (doi: 10.1016/j.biomaterials.2006.05.052).

68. Kinney M.A., Saeed R., McDevitt T.C. Systematic analysis of embryonic stem cell differentiation in hydrodynamic environments with controlled embryoid body size. Integrative Biology, 2012, 4(6): 641-650 (doi: 10.1039/c2ib00165a).

69. Dias A.D., Unser A.M., Xie Y., Chrisey D.B., Corr D.T. Generating size-controlled 
embryoid bodies using laser direct-write. Biofabrication, 2014, 6(2): 025007 (doi: 10.1088/1758-5082/6/2/025007).

70. Nakano Y., Iwanaga S., Mizumoto H., Kajiwara T. Evaluation of hollow fiber culture for largescale production of mouse embryonic stem cell-derived hematopoietic stem cells. Cytotechnology, 2018, 70(3): 975-982 (doi: 10.1007/s10616-018-0210-z).

71. Biesecker L.G., Emerson S.G. Interleukin-6 is a component of human umbilical cord serum and stimulates hematopoiesis in embryonic stem cells in vitro. Exp. Hematol., 1993, 21(6): 774-778.

72. Lieschke G.J., Dunn A.R. Development of functional macrophages from embryonal stem cells in vitro. Exp. Hematol., 1995, 23(4): 328-334.

73. Matsumoto K., Isagawa T., Nishimura T., Ogaeri T., Eto K., Miyazaki S., Miyazaki J., Aburatani H., Nakauchi H., Ema H. Stepwise development of hematopoietic stem cells from embryonic stem cells. PLoS ONE, 2009, 4(3): e4820 (doi: 10.1371/journal.pone.0004820).

74. Burt R.K., Verda L., Kim D.A., Oyama Y., Luo K., Link C. Embryonic stem cells as an alternate marrow donor source: engraftment without graft-versus-host disease. J. Exp. Med., 2004, 199(7): 895-904 (doi: 10.1084/jem.20031916).

75. Dang S.M., Gerecht-Nir S., Chen J., Itskovitz-Eldor J., Zandstra P.W. Controlled, scalable embryonic stem cell differentiation culture. Stem Cells, 2004, 22(3): 275-282 (doi: 10.1634/stemcells.22-3-275).

76. de Souza G.T., Maranduba C.P., de Souza C.M., do Amaral D.L., da Guia F.C., Zanette Rde S., Rettore J.V., Rabelo N.C., Nascimento L.M., Pinto H.F., Farani J.B., Neto A.E., Silva Fde S., Maranduba C.M., Atalla A. Advances in cellular technology in the hematology field: What have we learned so far? World J. Stem Cells, 2015, 7(1): 106-115 (doi: 10.4252/wjsc.v7.i1.106).

77. Hume D. The mononuclear phagocyte system. Current Opinion in Immunology, 2006, 18(1): 4953 (doi: 10.1016/j.coi.2005.11.008).

78. Geissmann F., Manz M.G., Jung S., Sieweke M.H., Merad M., Ley K. Development of monocytes, macrophages and dendritic cells. Science, 2010, 327(5966): 656-661 (doi: 10.1126/science.1178331).

79. Ginhoux F., Guilliams M. Tissue-resident macrophage ontogeny and homeostasis. Immunity, 2016, 44(3): 439-449 (doi: 10.1016/j.immuni.2016.02.024).

80. McGrath K.E., Frame J.M., Palis J. Early hematopoiesis and macrophage development. Seminars in Immunology, 2015, 27(6): 379-387 (doi: 10.1016/j.smim.2016.03.013).

81. Pittet M.J., Nahrendorf M., Swirski F.K. The journey from stem cell to macrophage. Ann. N. $Y$. Acad. Sci., 2014, 1319(1): 1-18 (doi: 10.1111/nyas.12393).

82. Young D.A., Lowe L.D., Clark S.C. Comparison of the effects of IL-3, granulocyte-macrophage colony-stimulating factor, and macrophage colony-stimulating factor in supporting monocyte differentiation in culture. Analysis of macrophage antibody-dependent cellular cytotoxicity. Journal of Immunology, 1990, 145(2): 607-615.

83. Moore K.J., Fabunmi R.P., Andersson L.P., Freeman M.W. In vitro-differentiated embryonic stem cell macrophages: a model system for studying atherosclerosis-associated macrophage functions. Arteriosclerosis, Thrombosis, and Vascular Biology, 1998, 18(10): 1647-1654 (doi: 10.1161/01.atv.18.10.1647).

84. Zhuang L., Pound J.D., Willems J.J., Taylor A.H., Forrester L.M., Gregory C.D. Pure populations of murine macrophages from cultured embryonic stem cells. Application to studies of chemotaxis and apoptotic cell clearance. Journal of Immunological Methods, 2012, 385(1-2): 1-14 (doi: 10.1016/j.jim.2012.06.008).

85. Subramanian A., Guo B, Marsden M.D., Galic Z., Kitchen S., Kacena A., Brown H.J., Cheng G., Zack J.A. Macrophage differentiation from embryoid bodies derived from human embryonic stem cells. J. Stem Cells, 2009, 4: 29-45.

86. Savchenkova I.P., Savchenkova E.A., Osipova Yu.A. Geny i kletki, 2019, 14(S1): 202-203 (in Russ.).

87. Savchenkova I.P., Savchenkova E.A. Vestnik transplantologii i iskusstvennykh organov, 2019, XXI(S): 160 (in Russ.). 